\title{
Performance Analysis of Different Loss MECHANISMS IN OPTICAL FibER COMMUNiCATION
}

\author{
Md. Nasir Uddin, Dr M. Mahbubur Rahman, Md. Sadek Ali \\ Communication Research Laboratory, Dept. of Information \& Communication \\ Engineering \\ Islamic University, Kushtia 7003, Bangladesh.
}

\begin{abstract}
This paper deals with different loss mechanisms within the single mode fiber (SMF) in optical fiber communication. A number of mechanisms are responsible for the signal attenuation within optical fibers. As the optical signal propagates over long stretch of fiber, it becomes attenuated because of absorption, scattering, fiber bends by material impurities, and other effects. The transmission using high bandwidth can handle vast amounts of information, which can be further improved by reduction in fiber losses, increase in data rates and distances, and using appropriate operating wavelength in optical fiber communication. The recent development in the area of fiber optic communication as well as the advances in different fiber types and their properties such as attenuation or loss and bandwidth are also discussed in this paper. The performance improvement of the proposed different loss, such as Rayleigh scattering, Stimulated Brillouin Scattering (SBS), Stimulated Raman Scattering (SRS), and bending loss within the various loss mechanisms in fiber optic communication is shown through simulations.
\end{abstract}

\section{KEYWORDS}

Optical fibers, SMF, SBS, SRS, and bending loss.

\section{INTRODUCTION}

In the communication age, technologies seeing a relentless demand for networks of higher capacities at lower costs. Recent advances in data processing capabilities brought about by the development of high speed and high-density integrated circuits have surpassed existing data transmission capabilities. The use of large bundles of copper wires is becoming less desirable as a means of information transfer. The size, weight, bandwidth limitations, and cost of metal conductors have forced scientists and engineers to investigate other means of data handling. From the several alternatives being developed, fiber optics is one of the most important and costeffective solutions for the communication [1].

Optical fiber communication technology has developed rapidly to achieve larger transmission capacity and longer transmission distance. Fiber optics offers potential advantages in size, weight, bandwidth (i.e. $10^{13}$ to $10^{14} \mathrm{~Hz}$ ), resistance to electromagnetic interference (EMI) and nuclear radiation, and cost when compared with metallic conductors [2]. In a number of applications, however, these advantages are of little or no consequence unless the implementation of fiber optics can also provide reliable data transmission capabilities over the expected life of the system. The recent interest in the use of fiber optic data links in military/defense applications has created a need for a reliable prediction methodology capable of addressing the various components and 
assemblies used in such a system. However, during information transmission in optical fiber communication it faced several attenuations, which reduce the performance of the system. The aim of this paper is to analysis the different loss mechanisms within single mode fiber and how to reduce these losses in optical fiber communication.

The rest of the paper is organized as follows: In section 2 deals with literature review. Section 3 describes the optical fiber communication model. Section 4 describes the optical fiber communication losses mechanisms. Section 5 describes the simulation results and finally section 6 concludes the paper.

\section{LITERATURE REVIEW}

As early as 1980, Alexander Graham bell reported the transmission of speech using a light beam [3]. During the middle of the twentieth century, it was realized that an increase of several orders of magnitude of bit rate distance product would be possible if optical waves were used as the carrier [4]. Narimanov Evgenii E., and Partha Mitra have developed a method to calculate the information capacity of a nonlinear channel and computed the decrease in channel capacity for fiber optic communication systems [5]. At lower pump powers, it is also possible to generate a simple Raman continuum of wavelengths, which can serve as a broadband source. Such a source has been demonstrated to be 324-nm wide and with a spectral power density greater than $10 \mathrm{~mW} / \mathrm{nm}$ [6]. A 36-channel $10-\mathrm{GHz}$ pulse source has been realized in a normally dispersive holey fiber by slicing a super continuum spectrum through an arrayed-waveguide grating [7]. Durana et al. studied the dependence of bending losses on plastic optical fibers (POFs) cladding thickness, through numerical results, using a ray-tracing model. Despite the obtained results, this approach is a time consuming procedure, since optical fibers with high numerical aperture (NA) allow nearly two million propagating rays. Each ray path, reflection point and new path is obtained using relative motion concepts [8]. Bunge et al. have theoretically investigated a ring launching scheme based on hollow optical fiber (HOF) to increase the bandwidth for multimode Gigabit Ethernet communication [9]. On a broader context, the research interest in slow and fast light has drawn the attention of the photonics research community to further investigate the phenomenon of SBS in optical fibers. Recent contributions include the realization of stored light based on SBS [10]

Sheng $\mathrm{Li}$ has reviewed the emerging technologies for advancing the fibre optic data communication bandwidth for the next generation broadband networks [11]. Zhou et al. systematically analyzed the security factors of Optic based Information Communication Infrastructure's (OICl) physical layer [12]. Fidler and Knapek performed the experimental field trials for optical communications from and to high-altitude platforms (HAPs) to transmit data at multi Gigabits per second [13]. Recent progresses in polymer technology and applications, including the improvement of transparency of the materials, have nowadays led to POF being considered a viable alternative to the dominant technologies in the marketplace [14]. Pham et al. experimentally demonstrated a simple, cost-effective hybrid gigabit fiber wireless system for in-building wireless access [15]. Li et al. experimentally demonstrated for the first time, millimeter wave(mm-wave) generation in the E-band (71-76 GHz and $81-86$ $\mathrm{GHz}$ ) based on photonics generation technique [16]. Xu et al. used a simple low cost and highly sensitivity fiber optical sensor system to measure the refractive index (RI) [17]. A novel technique was proposed by $\mathrm{Wu}$ et al. for modulation format-transparent polarization tracking and the de-multiplexing to identify the polarization state independently of the modulation format [18]. 


\section{Optical Fiber Communication System Model}

An optical fiber communication system is similar in basic concept to any type of communication system. Figure 1 shows an optical fiber communication system. In this case information source provides an electrical signal to a transmitter comprising an electrical stage which drives an optical source to give modulation of the light wave carrier. The optical source, which provides the electrical-optical conversion, may be either a semiconductor laser or light emitting diode (LED). The transmission medium consists of an optical fiber cable and the receiver consists of an optical detector, which drives a further electrical stage and hence provides demodulation of the optical carrier. Photodiodes (p-n, p-i-n or avalanche) and in some instances, phototransistors and photoconductor are utilized for the detection of the optical signal and the optical-electrical conversion. Thus there is a requirement for electrical interfacing at either end of the optical link and at present the signal processing is usually performed electrically. The optical carrier may be modulated using either an analog or digital information signal. In this system analog modulation involves the variation of the light emitted from the optical source in a continuous manner. With digital modulation, however, discrete changes in the light intensity are obtained. Although often simpler to implement, analog modulation with an optical fiber communication system is less efficient, requiring a far higher signal to noise ratio at the receiver than digital modulation.

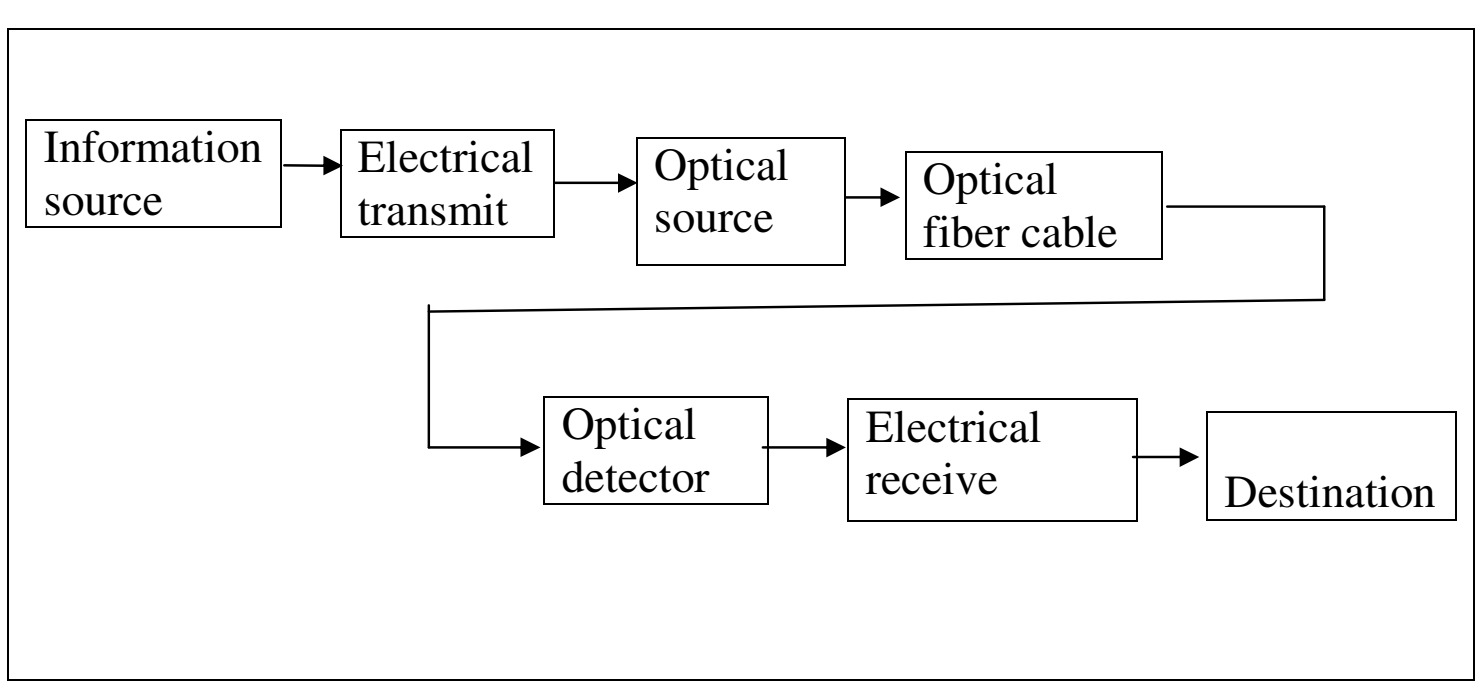

Figure 1. The optical fiber communication system

\section{Optical Fiber Communications Loss Mechanisms}

The Signal attenuation within optical fibers, as with metallic conductors, is usually expressed in the logarithmic units of the decibel. The decibel, which is used for comparing two power levels, may be defined for a particular optical wavelength as the ratio of the input (transmitted) optical power Pi into a fiber to the output(received) optical power Po from the fibers as:

$$
\text { Number of decibels }(\mathrm{dB})=10 \log \mathrm{Pi} / \mathrm{Po}
$$

This logarithmic unit has the advantage that the operations of multiplication and division reduce to addition and subtraction. whilst powers and roots reduce to multiplication and division. However, addition and subtraction require a conversion to numerical values which may be obtained using the relationship. 
In optical fiber communications the attenuation is usually expressed in decibels per unit length(i.e. $\mathrm{dB} / \mathrm{km}$ ) following:

$$
\alpha_{\mathrm{dB}} \mathrm{L}=10 \log \mathrm{Pi} / \mathrm{Po}
$$

where $\alpha \mathrm{dB}$ is the signal attenuation per unit length in decibels and $\mathrm{L}$ is the fiber length.

The various attenuation mechanisms are:

- Material absorption

- Linear scattering

- Non-linear scattering and

- Fiber bends

In this section, we describes the various loss mechanisms of linear scattering loss such as Rayleigh scattering, two non-linear scattering loss Stimulated Brilouin scattering(SBS), Stimulated Rayman Scattering and another type of loss is Fiber bends.

Rayleigh scattering is the most important scattering loss due to small localized changes in the refractive index of the core and the cladding material. These changes are due to two problems of manufacturing process: the fluctuations in the mix of the ingredients are impossible to completely eliminate and the slight change in the density as the silica cools and solidifies. The Rayleigh scattering loss in $\mathrm{dB} / \mathrm{km}$ can be approximated by the expression:

$$
\mathrm{L}=1.7 \times(0.85 / \lambda)^{4}
$$

Where, $\lambda$ is the wavelength in $\mu \mathrm{m}$ [19]. The scattering loss is inversely proportional to fourth power of wavelength. Therefore, Rayleigh scattering severally restricts the use of short wavelength in fiber optic communication.

Stimulated Brillouin Scattering(SBS) may be regarded as the modulation of light through thermal molecular vibrations within the fiber. The scattered light appears as upper and lower sidebands which are separated from the incident light by the modulation frequency. The incident photon in this scattering process produces phonon of acoustic frequency as well as a scattered photon. This produces an optical frequency shift which varies with the scattering angle because the frequency of the sound wave varies with acoustic wavelength. The frequency shift is a maximum in the backward direction reducing to zero in the forward direction making Brillouin scattering a mainly backward process. As indicated previously, Brillouin scattering is only significant above threshold power density. Assuming the polarization state of the transmitted light is not maintained, it may be shown that the threshold power $\mathrm{P}_{\mathbf{B}}$ is given by:

$P_{B}=4.4 \times 10^{-3} d^{2} \lambda^{2} \alpha_{d B} V$ watts

Or

$\alpha_{\mathrm{dB}=} \mathrm{P}_{\mathrm{B} \times 10}{ }^{3} /\left(4.4 \times \mathrm{d}^{2} \lambda^{2} \mathrm{v}\right)$

Where $\mathrm{d}$ and $\lambda$ are the fiber core diameter and the operating wavelength respectively. Both measured in micrometers, $\alpha_{\mathrm{dB}}$ is the fiber attenuation in decibels per kilometer and $\mathrm{v}$ is the source bandwidth (i.e. injection laser) in gigahertz. The expression given in which allows the determination of the threshold optical power which must be launched into a mono-mode optical fiber before Brillouin scattering occurs. 
Stimulated Raman scattering (SRS) is similar to stimulated Brillouin scattering except that a high frequency optical phonon rather than an acoustic phonon is generated in the Scattering process, Also. Raman scattering occurs in the forward direction and may have an optical power threshold of up to three orders of magnitude higher than the Brillouin threshold in a particular fiber. It may be shown that the threshold optical power for stimulated Raman scattering SRS $P_{R}$ in a long single mode fiber is given by:

$$
\mathrm{P}_{\mathrm{R}}=5.9 \times 10^{-2} \mathrm{~d}^{2} \lambda \alpha_{\mathrm{dB}} \text { watts }
$$

Or

$\alpha_{\mathrm{dB}}=\mathrm{P}_{\mathrm{R}} \times 10^{2} /\left(5.9 \times \mathrm{d}^{2} \lambda\right)$

Bend losses are particularly important in single-mode fiber. In these fibers, the bend losses show a dramatic increase above a critical wavelength when the fiber is bent or perturbed. In particular, it has been observed that the bend losses can be appreciably high at $1550 \mathrm{~nm}$ than in fibers designed for operation at $1310 \mathrm{~nm}$. The susceptibility of a fiber to these losses depends on the mode-field diameter and the cutoff wavelength. The worst-case condition is in a fiber with a large mode-field diameter and a low cut off wavelength, so Bending losses are minimized in single-mode fibers by avoiding this combination of that features.

Fibers show increased losses due to bending effects. Large bends of the cable and fiber are macro bends, Small scale bends in the core cladding interface are micro bends. These latter localized bends can develop during deployment of the fiber, or can be due to local mechanical stresses placed on the fiber (e.g., stresses induced by cabling the fiber or wrapping the fiber on a spool or bobbin). These latter losses are called the cabling loss and spooling loss, respectively. The output optical power of SMF is given by

$$
P_{o}(Z)=p_{i} \times 10^{-\alpha_{T} \cdot z / 10 d b}
$$

And the attenuation coefficient ( $\alpha$ bend) is given by

$$
\alpha_{b e n d}=c_{1} e^{-c_{2} r_{b}}
$$

Where (rb) is the radius of curvature of the fiber bend and (c1) and (c2) are constants. The losses are negligible until the radius reaches a critical size given by:

$r_{\text {crirical }} \approx \frac{3 n_{2} \lambda}{4 \pi(N A)^{3}}$

From this relation to minimize these losses, the fiber must be with a large NA and operated at a short wavelength. Fortunately, macro-bending does not cause appreciable losses until the radius of curvature of the bend is below (approximately) $1 \mathrm{~cm}$. This requirement does not present much problem in the practical utilization of fiber cables, but does present a minimum curvature to the fiber.

There is essentially no bending loss until a certain critical radius is reached, where upon the bending loss increases dramatically. Notice also that the critical bend radius is 
dramatically different for the two wavelengths. At $1310 \mathrm{~nm}$, the critical bend radius is about $1.5 \mathrm{~cm}$; and the bending losses is $0.2 \mathrm{~dB}$ at bending radius of $1.35 \mathrm{~cm}$. At $1550 \mathrm{~nm}$ the critical bend radius is about $2.5 \mathrm{~cm}$ (these critical bend radius change, depending on the fiber's numerical aperture and core radius ), so the bending loss is $8.3 \mathrm{~dB}$ at bending radius of $1.35 \mathrm{~cm}$, this bending losses was for $\mathrm{SiO} 2$ fiber.

\section{SYSTEM SimULATIONS}

\subsection{SiMULATION RESULTS OF RAYLEIGH SCATTERING LOSS IN SMF}

We have simulated the performance of Rayleigh scattering loss in fiber optics communication. From figure 2 we can say that loss of Rayleigh scattering be reduced by increasing the operating wavelength $\lambda$. The Rayleigh scattering loss only depends on the operating wavelength. So if we can use the operating wavelength above the $2 \mu \mathrm{m}$, the lower Rayleigh scattering loss occurs.

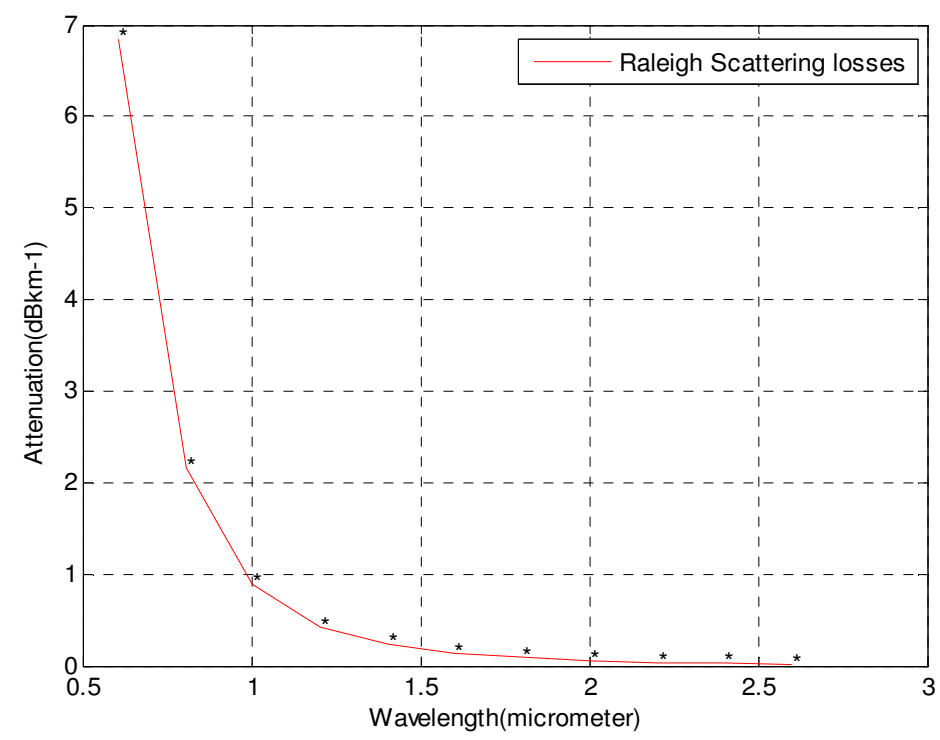

Figure 2. Output power of Rayleigh scattering for $\lambda=2.6 \mu \mathrm{m}$

\subsection{SimUlation RESUltS OF STIMULATEd BRILLOUIN SCATTERING LOSS IN SMF}

Stimulated Brillouin scattering loss have simulated, where threshold power $\mathrm{P}_{\mathrm{B}=} 80 \mathrm{mw}$, fiber core diameter $\mathrm{d}=6 \mu \mathrm{m}$, operating wavelength $\lambda=1.3 \mu \mathrm{m}$ and the laser source Bandwidth, $\mathrm{v}=600 \mathrm{MHz}$. Simulation result in figure 3 shows the curve of SBS loss in SMF. Observing the results we conclude that maximum power losses in the threshold optical power. Attenuation can be reduced by increasing the operating wavelength in SMF. 


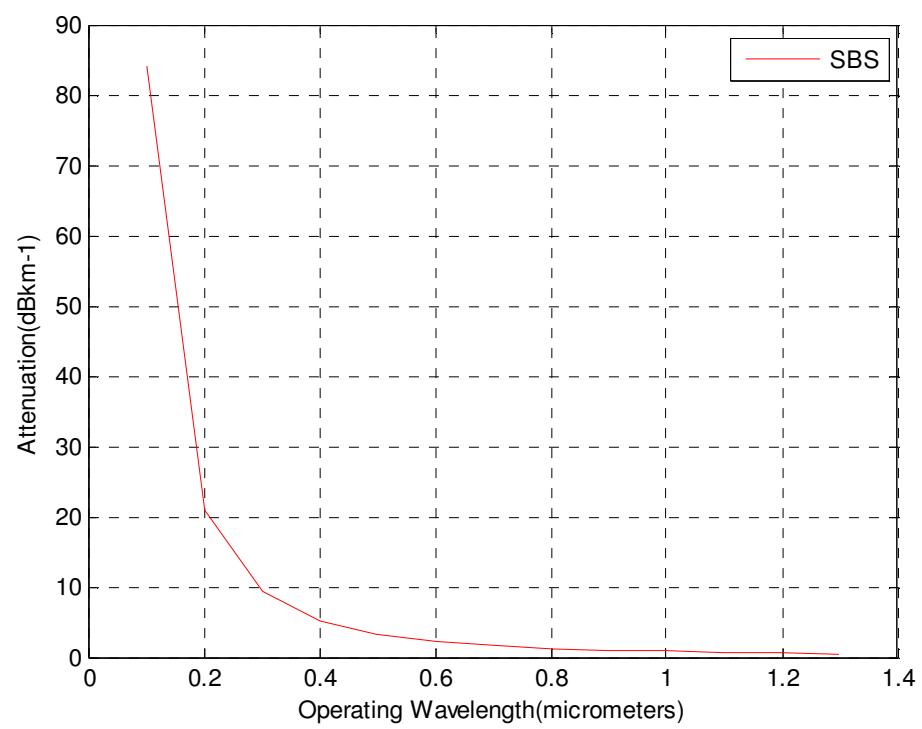

Figure 3. Output power of Simulated Brillouin scattering (SBS) for $\lambda=1.3 \mu \mathrm{m}$.

\subsection{SimUlation RESULTS OF STIMULATED RAMAN SCATTERING LOSS IN SMF}

Using threshold power $P_{R}=1380$, core diameter $d=6 \mu \mathrm{m}$ and operating wavelength $\lambda=1.3 \mu \mathrm{m}$, we simulate the results of Stimulated Raman scattering loss in SMF. Simulated results from figure 4 shown the above ten $\mathrm{dB} / \mathrm{km}$ maximum loss occur in the threshold optical power $1380 \mathrm{~mW}$. The loss are reduced after increase operating wavelength.

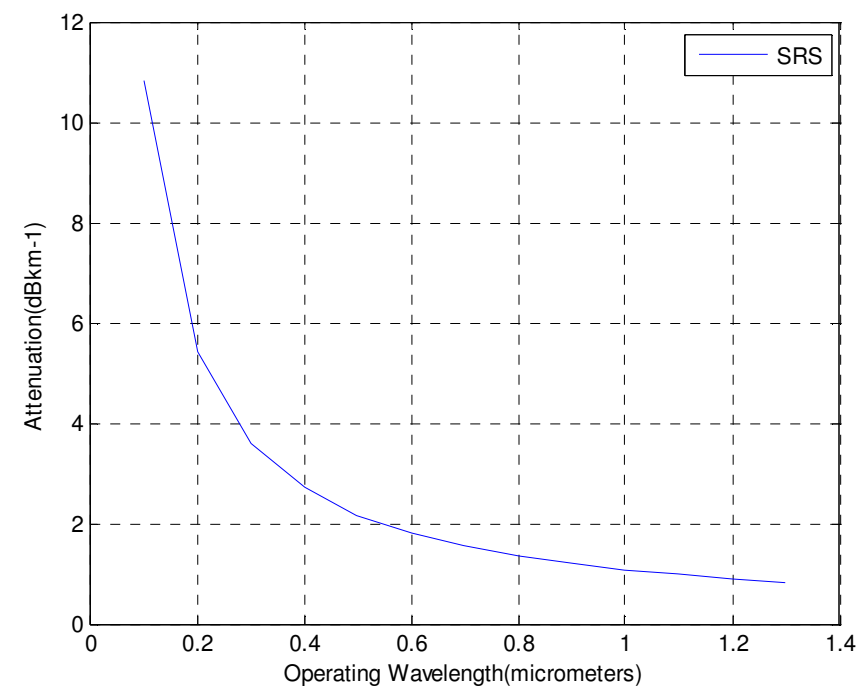

Figure 4. Output power of Simulated Raman scattering (SRS) for $\lambda=1.3 \mu \mathrm{m}$.

\subsection{COMPARISON THE SIMULATION RESULTS OF SBS AND SRS IN SMF}

From the simulation results in figure 5 can conclude that the Brillouin threshold occurs at an optical power level of around $80 \mathrm{~mW}$ whilst the Raman threshold is approximately seventeen 
times larger. It is therefore apparent that the losses introduced by nonlinear scattering may be avoided by use of a suitable optical signal level (i.e. working below the threshold optical power). SBS and SRS are not usually observed in multimode fibers because their relatively large core diameters make the threshold optical power level extremely high.

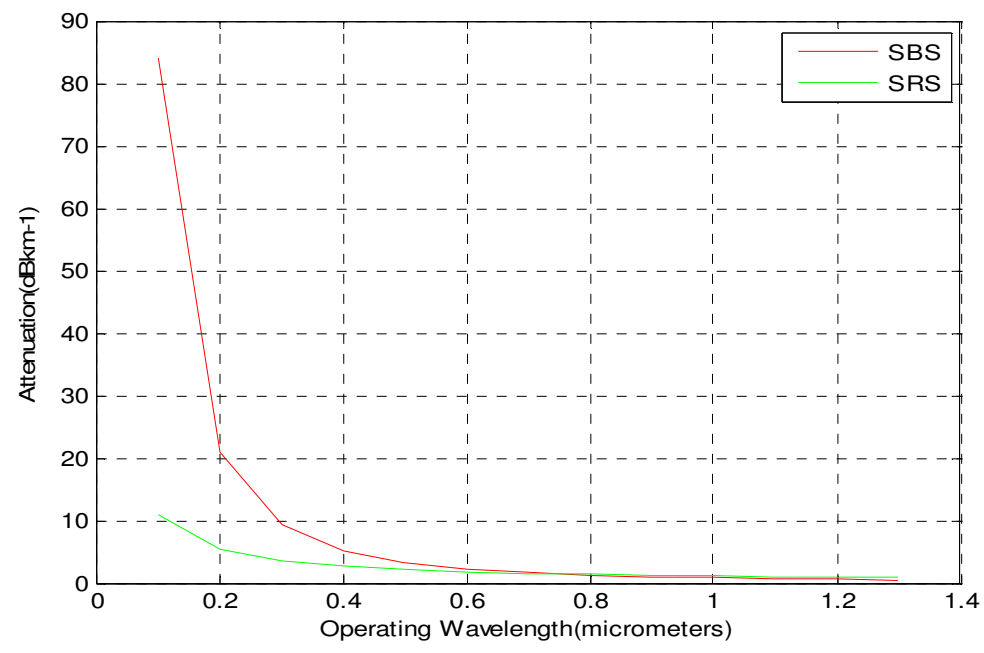

Figure 5. Comparison of SBS and SRS losses for $\lambda=1.3 \mu \mathrm{m}$

\subsection{SIMULATION RESULTS OF $\left(\mathrm{SIO}_{2}\right)$ SMF WITHOUT BENDING LOSS IN 1550NM}

The output power of $\left(\mathrm{SiO}_{2}\right) \mathrm{SMF}, \mathrm{n}_{1}=1.4516, \mathrm{n}_{2}=1.44462, \mathrm{NA}=0.1422, \alpha_{\mathrm{b}}=8.3, \alpha_{\mathrm{T}}=0.2 \mathrm{~dB} / \mathrm{km}$ simulates and results are shown in figure 6 .

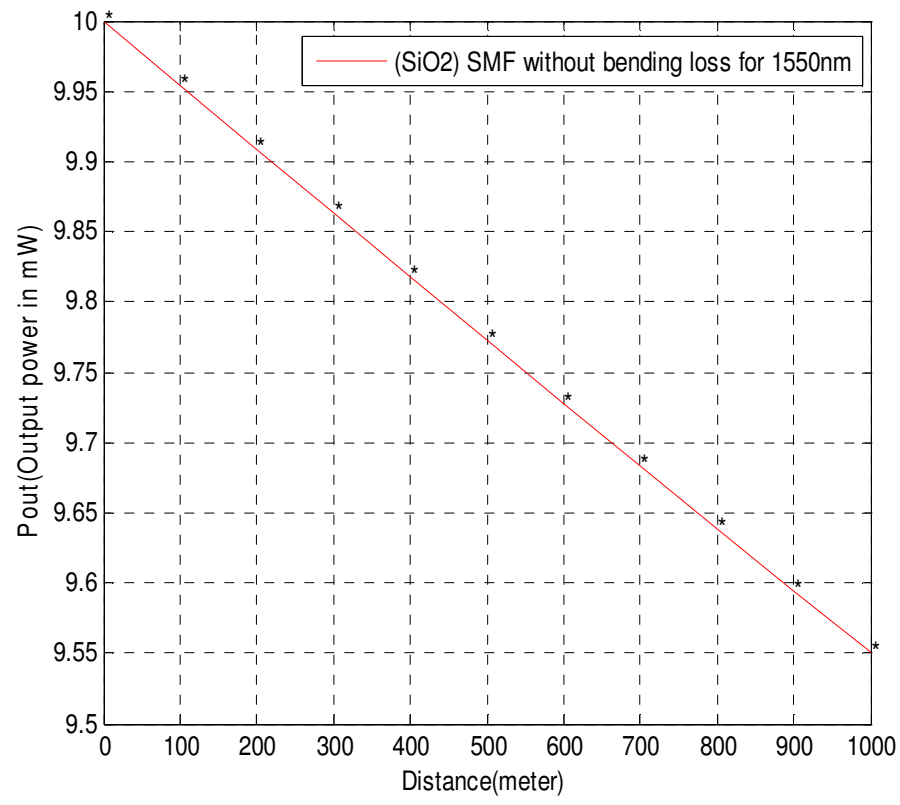

Figure 6. Output power without bending for $1550 \mathrm{~nm}$. 


\subsection{SIMULATION RESULTS OF (SIO2) SMF WITHOUT BENDING FOR 1310NM}

We have simulated the output power of $\left(\mathrm{SiO}_{2}\right) \mathrm{SMF}, \mathrm{n}_{1}=1.4516, \mathrm{n}_{2}=1.44462, \mathrm{NA}=0.1422$, $\alpha_{b}=0.2, \alpha_{\mathrm{T}}=0.34 \mathrm{~dB} / \mathrm{km}$ and results shows in figure 7. Also figure 8 illustrates the attenuation of two wavelength $1550 \mathrm{~nm}$ and $1310 \mathrm{~nm}$.

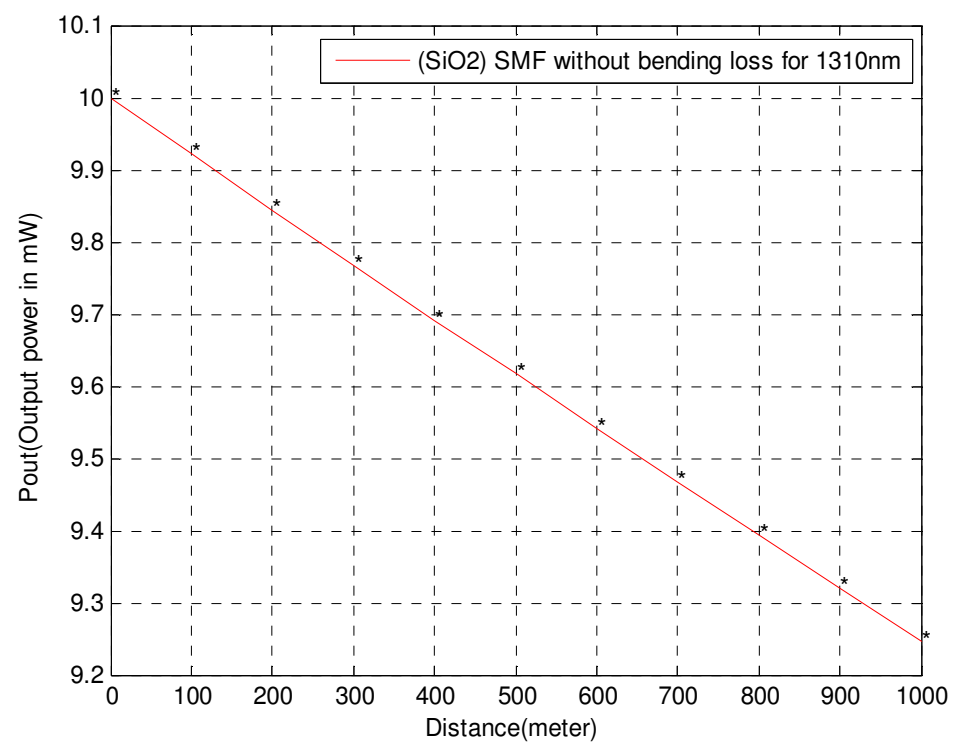

Figure 7. Output power without bending for 1310nm.

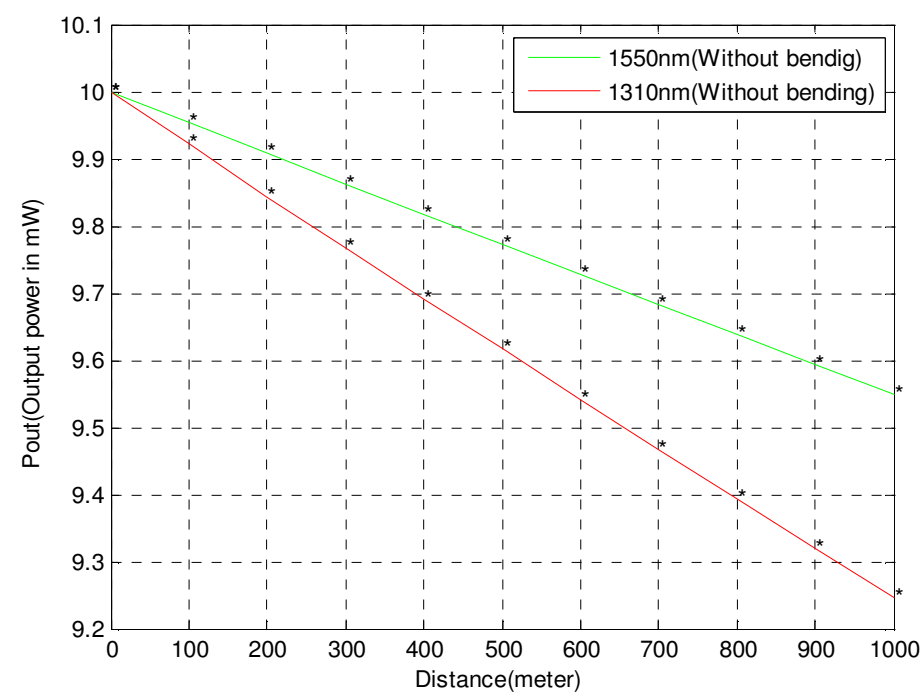

Figure 8. Attenuation of two wavelength $1550 \mathrm{~nm}$ and $1310 \mathrm{~nm}$. 


\subsection{SIMULATION RESULTS OF (SIO2) SMF WITH BENDING FOR 1550NM}

The output power of $(\mathrm{SiO} 2) \mathrm{SMF}, \mathrm{n} 1=1.4516, \mathrm{n} 2=1.44462, \mathrm{NA}=0.1422, \mathrm{Rc}=9.97 \mu \mathrm{m}, \alpha_{\mathrm{b}}$ $=8.3 \mathrm{~dB}, \alpha_{\mathrm{t}}=0.2 \mathrm{~dB} / \mathrm{km}$ have simulated and the results are shown in figure 9 .

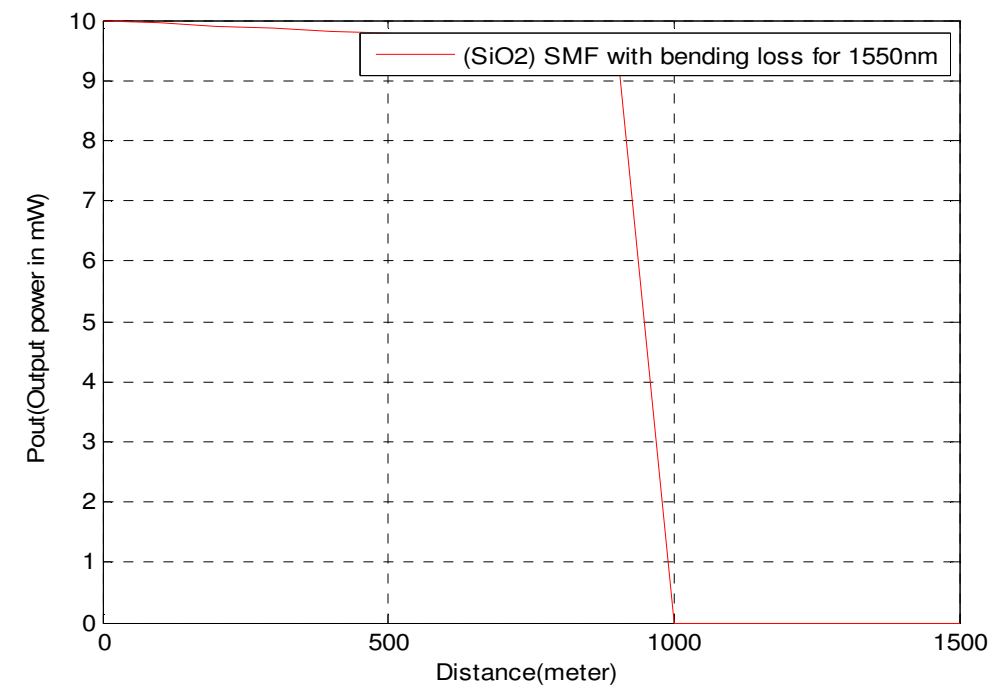

Figure 9. Output power with bending for 1550nm.

\subsection{SIMULATION RESULTS OF (SIO2) SMF WITH BENDING FOR 1310NM}

The output power of ( $\mathrm{SiO} 2) \mathrm{SMF}, \mathrm{n} 1=1.4524, \mathrm{n} 2=1.4468, \mathrm{NA}=0.1422, \mathrm{Rc}=8.427, \alpha \mathrm{b}=0.2 \mathrm{~dB}$, $\alpha \mathrm{T}=0.34 \mathrm{~dB} / \mathrm{km}$ have simulated and the simulation results are shown in figure 10 .

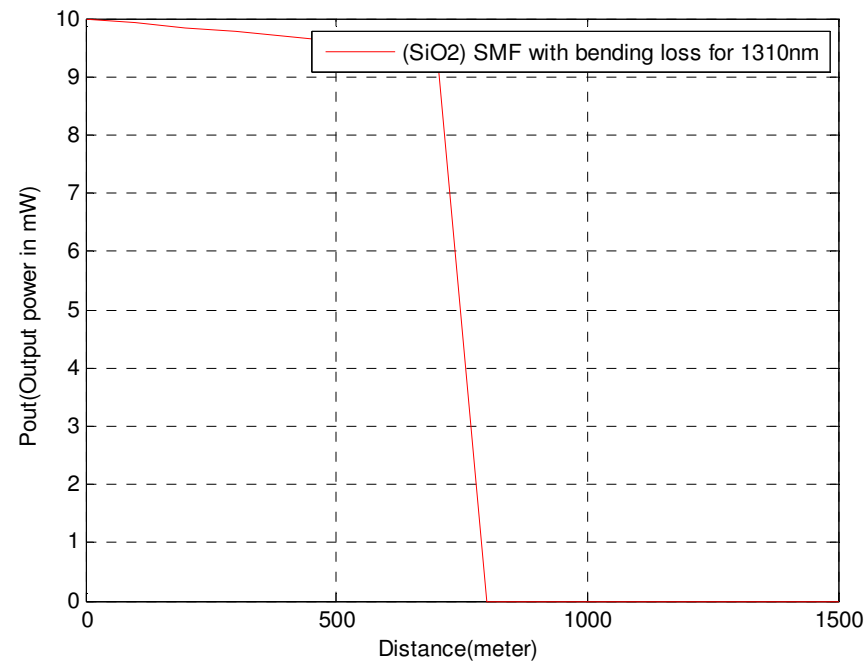

Figure 10. Output power with bending for $11310 \mathrm{~nm}$ 


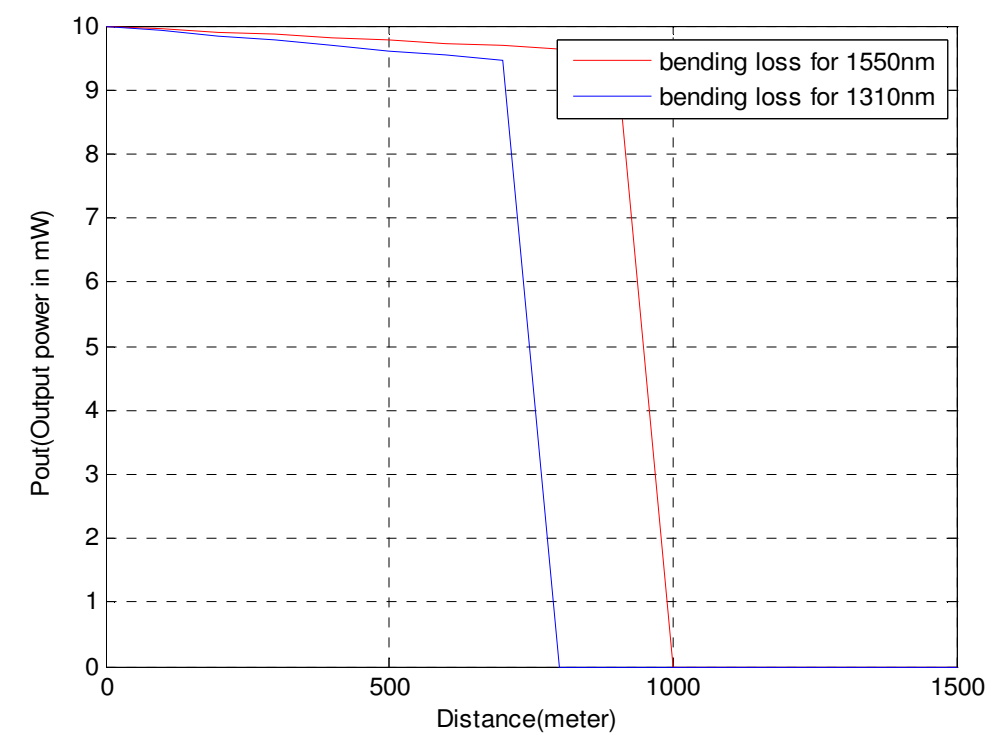

Figure 11. Bending losses of two wavelengths $1550 \mathrm{~nm}$ and $1310 \mathrm{~nm}$ of SMF.

\section{Conclusions}

In this paper, we have simulated the performance of Optical Fiber communication in Single Mode Fiber (SMF) using various loss mechanisms. Firstly we have observed linear scattering such as Rayleigh scattering from the simulation results, whereas Rayleigh scattering is strongly reduced by operating at the longest possible wavelength. Then we have observed two non-linear scattering Stimulated Brillouin scattering and Stimulated Raman scattering losses in fiber optic communication. From the results the Brillouin threshold occurs at an optical power level of around $80 \mathrm{~mW}$ whilst the Raman threshold is approximately seventeen times larger. It is therefore apparent that the losses introduced by non-linear scattering may be avoided by use of a suitable optical signal level (i.e. working below the threshold optical powers). SBS and SRS are not usually observed in multimode fibers because their relatively large core diameters make the threshold optical power levels extremely high. It should be noted that the threshold optical powers for both these scattering mechanisms may be increase by suitable adjustment of the others parameters in loss mechanisms..Finally, we have simulated the bending loss by and conclude that the loss is negligible until the radius reaches a critical size. To minimize these losses, the fiber must be with a Large NA and operated at a short wavelength. The losses of bending simulates in $\mathrm{SiO} 2-\mathrm{SMF}$ by using two wavelength $(13310 \mathrm{~nm}, 1550 \mathrm{~nm})$ with simulations. The attenuation of $1310 \mathrm{~nm}$ is greater than $1550 \mathrm{~nm}$ but in bending the losses of $1550 \mathrm{~nm}$ is greater than $1310 \mathrm{~nm}$.

Further research will be aimed at developing and analysis the linear (Rayleigh) and nonlinear(SBS, SRS) scattering loss mechanisms in multimode optical fibers through simulation. The effect of different bending and bending losses with different Wavelengths will also be simulated. 


\section{REFERENCES}

[1] RADC-TR-80-322 Final Technical Report October 1980, FAILURE RATES FOR FIBER OPTIC ASSEMBLIES NT Research Institute.

[2] J. Senior, Optical Fiber Communications Principles, and Practice, (Prentice-Hall, Englewood Cliffs, New Jersey, 1985), pp 11.

[3] M.C. brierley, P.W. France,R. A. Granham, C.A. Millar and W.A. Stallard, Long wevelangth fluoride fiber system using a $2.7 \mu \mathrm{m}$ fluoride fiber laser, Proc. Optical Fiber Commun.Conf.,OFC'89(USA), Postdealing paper, PD-14,February 1989.

[4] T Okoshi and K Kikuchi, Coherent optical fiber communication (Kluwer Academic, Boston, 1988)

[5] Narimanov Evgenii E., and Partha Mitra, - The Channel Capacity of a Fiber Optics Communication System: Perturbation Theoryll Journal of Light wave Technology, Vol. 20, No. 3, pp. 530-537, 2002.

[6] A. V. Avdokhin, S. V. Popov, and J. R . Taylor, "Continuous-wave, high-power, Raman continuum in holey fibers," Opt. Lett., vol. 28, no. 15, pp. 1353-1355, Aug. 1, 2003.

[7] Z. Yousoff, P. Petropoulos, K. Furusawa, T. M. Monro, and D. J. Richardson, "A 36-channel-10 GHz spectrally sliced pulse source based on supercontinuum generation in a normally dispersive highly non- linear holey fiber,” IEEE Photon. Technol. Lett. , vol. 15, no. 12, pp. 1689-1691, Dec. 2003.

[8] Durana, G.; Zubia, J.; Arrue, J.; Aldabaldetreku, G.; Mateo, J. Dependence of bending losses on cladding thickness in plastic optical fibers. Appl. Opt. 2003, 42, 997-1002

[9] Bunge S. Choi, K. Ohb, - Analysis of ring launching scheme using hollow optical fibre mode converter for $10 \mathrm{Gbps}$ multimode fibre communication\| Optical Fibre Technology 12,pp48-58, 2006

[10] Z. Zhu, D. J. Gauthier, and R. W. Boyd, " Stored light in an optical fiber via stimulated Brillouin scattering," Science 318, 1748- 1750 (2007).

[11] Sheng Li Chung, -Emerging Technology for fibre optic data communication\| Handbook of fibre optic data communication, III Edition, chapter 25, 2008.

[12] Ling Zhou, Xi Chen, Zhao Ziyan, Li lianqi, - Research in security of optic-based information communication architecture for next generation power system applications Conference on Power System Technology,pp. 1-5, 2010

[13] Fidler Franz, Markus Knapek, Joachim Horwath, and R. Walter Leeb —Optical Communications for High-Altitude Platforms\| IEEE Journal of Selected Topics In Quantum Electronics, Vol. 16, NO. 5, September/October 2010.

[14] Koike, Y.; Koike, K. Progress in low-loss and high-bandwidth plastic optical fibers. J. Polym. Sci. B Polym. Phys. 2011, 49, 2-17.

[15] Pham Tien-Thang, Alexander Lebedev, Marta Beltrán, Xianbin Yu, Roberto Llorente, Idelfonso Tafur Monroy, —Combined single-mode/multimode fibre link supporting simplified in-building 60-GHz gigabit wireless access\|Optical Fibre Technology 18, 226-229, 2012

[16] Li Xinying, 1 Jianjun Yu, 1Ze Dong, and Nan Chi1, _"Photonics Millimeter-Wave Generation in the E-Band and Bidirectional Transmission" IEEE Photonics Journal, Vol. 5, No. 1, 2013.

[17] XuWei, XuGuang Huang, and Jing Shun Pan, -Simple Fibre-Optic Refractive Index Sensor Based On Fresnel Reflection and Optical Switch\| IEEE Sensors Journal, Vol. 13, NO. 5, pp. 15711574, 2013.

[18] Wu Zifeng, Schmidt Daniel, and Lank Berthold, -Modulation-Format-Transparent Polarization Tracking Using a Neural Network\| IEEE Photonics Technology Letters, Vol. 25, No. 7, pp- 671674,2013.

[19] www.ijetae.com ISSN 2250-2459, ISO 9001:2008 Certified Journal, Volume 3, Issue 5, May 2013 


\section{AUTHORS}

Md. Nasir Uddin received the Bachelor's Degree in the Dept. of Information and Communication Engineering (ICE) from Islamic University, Kushtia, in 2011. He is currently student of Master's Degree in the department of ICE, Islamic University, Kushtia-7003 Bangladesh. He has currently researched in the same field in the Laboratory of ICE, Islamic University, Kushtia-7003, Bangladesh. His areas of interest include Optical fiber communication, Wireless Communications, Spread Spectrum and mobile communication

Dr. M. Mahbubur Rahman received his B. Sc. and M. Sc from Rajshahi University in Physics. He is currently working as Professor in the department of Information \& Communication Engineering, Islamic University, Kushtia-7003, and Bangladesh.

Md. Sadek Ali received the Bachelor's and Master's Degree in the Department of Information and Communication Engineering (ICE) from Islamic University, Kushtia, in 2004 and 2005 respectively. He is currently assistant professor in the department of ICE, Islamic University, Kushtia-Bangladesh. Since 2003, he has been working Research Scientist at the Communication Research Laboratory, Department of ICE, Islamic University, Kushtia, where he belongs to the spread-spectrum research group. He has five

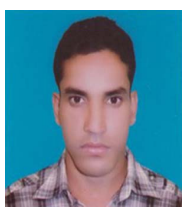
published paper in international and two national journals in the same areas. His areas of interest include Wireless Communication, optical fiber communication, Spread Spectrum and mobile communication. 